\title{
Correction to: DNA Damage In situ Ligation followed by Proximity Ligation Assay (DI-PLA)
}

\section{Alessandro Galbiati and Fabrizio d'Adda di Fagagna}

\section{Correction to:}

Chapter 2 in Marco Demaria (ed.),

Cellular Senescence: Methods and Protocols, Methods in Molecular Biology, vol. 1896, https://doi.org/10.1007/978-1-4939-8931-7_2

The acknowledgements listed below have been added to the chapter.

Work in Fabrizio d'Adda di Fagagna's laboratory is supported by the Associazione Italiana per la Ricerca sul Cancro, AIRC (application 12971), Cariplo Foundation (grant 2010.0818 and 2014-0812), Fondazione Telethon (GGP12059 and GGP17111), Association for International Cancer Research (AICR-Worldwide Cancer Research Rif. N. 14-1331), the Italian Ministry of Education Universities and Research EPIGEN Project, a European Research Council advanced grant (322726), AriSLA (project "DDRNA and ALS”), AIRC Special Program 5 per mille metastases Project n 21091, AMANDA project Accordo Quadro Regione Lombardia-CNR, and flagship progetto InterOmics.

The updated online version of this chapter can be found at https://doi.org/10.1007/978-1-4939-8931-7_2 